\title{
HOMEOWNERSHIP: LOW HOUSEHOLD MOBILITY, Volatile Housing PRices, High InCOME DISPERSION
}

\author{
FRANÇOIS ORTALO-MAGNÉ \\ SVEN RADY
}

\author{
CESIFO WORKING PAPER NO. 823 \\ CATEGORY 10: EMPIRICAL AND THEORETICAL METHODS
}

DECEMBER 2002 


\title{
HOMEOWNERSHIP: LOW HOUSEHOLD Mobility, Volatile Housing PRICES, HIGH INCOME DISPERSION
}

\begin{abstract}
We develop a dynamic stochastic equilibrium model of two locations within a city where heterogeneous households make joint location and tenure mode decisions. To investigate the effect of homeownership on equilibrium prices and allocations, we compare the response of this model economy to a labor shock with that of a rental-only version. This comparison yields three results. First, homeownership enables more households to remain in the more desirable location at the expense of newcomers. Second, homeownership adds to the volatility of the housing market. Third, homeownership may amplify the dispersion of household income within a location. Homeownership raises distributional issues. The households who consume the most housing gain the most from the ability to own their home. Newcomers to the city are the main losers.
\end{abstract}

JEL Classification: D11, D31, D58, R21, R23.

François Ortalo-Magné

London School of Economics

Houghton Street

London WC2A $2 A E$

England

ortaloma@lse.ac.uk

\author{
Sven Rady \\ University of Munich \\ Department of Economics \\ Kaulbachstr. 45 \\ 80539 Munich \\ Germany \\ sven.rady@lrz.uni-muenchen.de
}

Our thanks for helpful comments and discussion are due to Tom Davidoff, Bob Edelstein, Richard Green, Joe Gyourko, Erzo G.J. Luttmer, Chris Mayer, Todd Sinai, Nick Souleles, Susan Wachter, and seminar participants at the Lincoln Institute, the 2002 NBER Summer Institute, the University of California at Berkeley, Carnegie Mellon, the University of Pennsylvania, the University of Southern California, and the University of Wisconsin. The hospitality and support of the Lincoln Institute and the Center for Economic Studies at the University of Munich are gratefully acknowledged. 
This paper studies how homeownership affects local housing markets and the distribution of households across residential properties. Housing differs from other durable consumption goods insofar as a housing purchase is typically tied to the purchase of land, a durable which does not depreciate. This makes housing a desirable asset to hold in one's portfolio as a hedge against shocks to the local economy. The novelty of the present paper is to embed key features of existing models of household tenure choice into an equilibrium framework where heterogeneous households choose both housing consumption and tenure.

This framework enables us to analyze formally the type of issues raised in the following concrete example. Let us consider the case of taxicab drivers in central London who do not expect their income to grow as fast as local housing costs. If they want to live in central London and remain there for years, they have a strong incentive to buy their home. Buying a home allows them to set their monthly housing expenditures to a known level, independent of future rent fluctuations. If the London economy booms, attracting new economic activity and new workers, the resulting pressure on the housing market will force housing costs upward. Since the taxicab drivers own their home, they enjoy capital gains. The increase in the opportunity cost of their home may lead some to move out of central London, but not as many as if they had been renting. This low mobility of local homeowners adds upward pressure on the housing market. Faced with higher central London housing rents and prices, the new workers moving into central London are fewer and richer. This helps explain the high levels of income heterogeneity we observe within neighborhoods - neighborhoods where, for example, taxicab drivers live next to newly arrived investment bankers.

The example captures the main insights gathered from our model as far as the effects of homeownership are concerned. Without homeownership, more households move out of the prime location given one and the same price rise. As a consequence, the cost of housing in the prime location does not rise as much in response to a positive shock. The lower rise in housing cost incites a broader cross-section of new workers to move into the prime location, hence less income disparity between the newcomers and the native households who do not move.

Homeownership raises first and foremost distributional issues. Although the incoming teachers may have the higher level of human capital, they find themselves living in worse accommodation than the taxicab drivers who benefited from getting on the 
property ladder ahead of the boom. The taxicab drivers enjoy capital gains; they win. The newcomers face higher housing costs; they lose. With homeownership, the wealth of a household who owns its home depends on its past fortunes on the housing market, and so does its housing consumption. Without homeownership, the distribution of homes across households is closer to the distribution of human capital.

Our results on income dispersion provide a new explanation for a long-standing puzzle in the literature concerning the distribution of households across communities: standard models predict too much stratification of households according to income into overly homogeneous communities. ${ }^{1}$ This is particularly the case for static models concerned with mobility among local jurisdictions. These models assume a single dimension of household heterogeneity. ${ }^{2}$ Bénabou (1993) showed that stratification also arises in a dynamic model with local complementarities in human capital investment and endogenously determined local land rents. ${ }^{3}$ To obtain some degree of income heterogeneity within communities, Epple and Platt (1998) and Epple and Sieg (1999) extend the local jurisdiction model by assuming that households differ not only in terms of income, but also in terms of preferences. Here we propose an alternative explanation for imperfect stratification based on the fact that the wealth distribution may differ from the income distribution owing to the heterogeneity of households' housing market experiences.

The key feature of the housing market we focus on is the inability of households to vary their exposure to housing returns independently of their consumption of housing services. This is a problem of market incompleteness. Recent research has explored the significance of the resulting insurance motive for homeownership at the household level and reports evidence that differences between the financial risks of renting and of owning are significant drivers of housing tenure choices. ${ }^{4}$ A discussion of this literature is provided in Ortalo-Magné and Rady (2002).

We obtain our results without introducing a further dimension of market incompleteness relevant to the housing market: credit constraints. There is ample empirical

\footnotetext{
${ }^{1}$ E.g., Epple and Platt (1998), Ioannides (2001), Ioannides and Seslen (2001).

${ }^{2}$ See Epple, Filimon, and Romer $(1984,1993)$ and Goodspeed (1989) for examples of such models with a housing market.

${ }^{3}$ Along the same line of research, Durlauf (1996) proposes a model of communitywide influences on individual attainment where income requirements proxy for zoning restrictions.

${ }^{4}$ E.g., Davidoff (2001), Hilber (2002), Sinai and Souleles (2001).
} 
evidence that credit constraints may override other concerns in the tenure decision for a subset of households. ${ }^{5}$ While we acknowledge the determinant role credit constraints play in the tenure decision of a subset of households, we focus here on the equilibrium interaction of households sufficiently wealthy that credit constraints are not likely to affect their tenure choice. ${ }^{6}$

The paper is organized as follows. Section 1 presents the model. In Section 2, we consider the decision problem of an individual household. Section 3 determines the equilibrium allocation and prices. Section 4 compares this equilibrium with its counterpart in a rental-only version of the model. Section 5 offers some concluding remarks. All proofs are in the appendix.

\section{The Model}

We consider a two-period model of a city with two locations, 1 and 0 . Initially, the city is populated by a measure one of households. These native households are distributed uniformly over the unit interval, each being identified by an index $i \in[0,1]$. Over its lifetime, household $i$ receives a stream of endowments of the numeraire good whose capitalized value in period 2 is $W(i)$, an increasing continuous function of $i$.

At the start of each period, a native household may either buy or rent a single home for own use in one of the two locations. The household derives additively separable utility from the consumption of housing and the numeraire good. Housing is enjoyed at the end of periods 1 and 2, the numeraire good only at the end of period 2. There is no discounting of housing utility across periods. For concreteness, we assume that location 1 is more desirable than location 0 : housing utility derived from a home in location 0 is normalized to zero, whereas a home in location 1 yields an additive utility premium of $\mu>0$ per period, independent of tenure. The non-housing utility derived from consumption of $c$ units of the numeraire good is described by the constant absolute risk aversion function $U(c)=-e^{-a c}$ where $a>0$ is the coefficient of absolute risk aversion.

\footnotetext{
${ }^{5}$ E.g., Linneman and Wachter (1989), Ortalo-Magné and Rady (1999), Chiuri and Jappelli (forthcoming).

${ }^{6}$ Haavio and Kauppi (2002) argue that credit constraints in the housing market reduce labor mobility.
} 
Native households face uncertainty about the cost of housing in the second period because the city is potentially subject to a population shock at the start of period 2. With probability $\pi$ strictly between 0 and 1 , a measure $\nu$ of newcomer households arrives (state $H$ ); with the complementary probability, no shock occurs (state $L$ ). Like native households, newcomers are distributed uniformly over the unit interval; they are characterized by the index $n \in[0,1]$. Their endowment is defined by the increasing and continuous function $\tilde{W}(n)$. They have the same utility function as natives adjusted for the fact that they cannot obtain any utility from housing in period 1. The only decision they face is whether to live in location 1 or 0 in the second period and how much of the numeraire good to consume.

The supply of housing in location 0 is perfectly elastic at a price normalized to zero. The supply of housing in location 1 is perfectly inelastic: at the start of period 1, absentee landlords own a measure $S$ of homes there. For reasons that will become

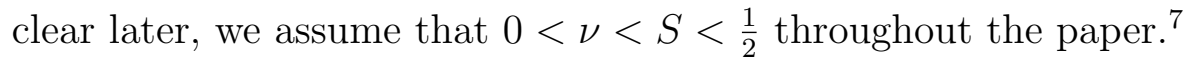

The landlords are risk neutral and do not derive any consumption benefit from owning properties. Their sole investment alternative is a savings technology available to all. All agents can save or borrow between periods 1 and 2 at the exogenously given interest rate $r$.

As period 2 is the last period of the economy, renting a home in period 2 is equivalent to buying it, so the price of a home in period 2 coincides with the rental cost of that home in period 2. Moreover, arbitrage on the part of the landlords ensures that the price of a home in period 1 equals the first-period rent plus discounted expected secondperiod rent. For a home in location 1, this means that the first-period price is

$$
p_{1}=R_{1}+\frac{\bar{R}_{2}}{1+r}
$$

where $R_{1}$ denotes the first-period rent and $\bar{R}_{2}=\pi R_{H}+(1-\pi) R_{L}$ the expected second-period rent.

For a home in location 0 , the normalization of rents to zero implies that the firstperiod price is zero as well by the analogue of equation (1). This means in particular

\footnotetext{
${ }^{7}$ For the sake of simplicity and without loss of generality, we assume extreme differences in the supply of housing between the two locations. The key feature here is that the supply of housing in 1 is less elastic than in 0 . The assumptions on $\nu$ and $S$ are for ease of exposition.
} 
that it makes no difference for a household wishing to live in location 0 in the first period whether it rents or buys its home.

Equation (1) highlights what ownership means in this model: by purchasing a home in the first period, a household effectively signs a two-period rental contract, locking in the second-period rent at its expected level. If the household plans to stay in location 1 in the second period, purchasing the home in the first period provides insurance against rent fluctuations. Whether buying in location 1 instead of renting is more or less risky therefore depends on the household's planned housing consumption in the second period. If the household plans to stay in location 1 in the second period, buying provides insurance against rent fluctuations. If it plans to sell and move to location 0 , buying provides exposure to potential capital gains or losses.

With two periods, the model therefore captures the empirically supported hypothesis that at short horizons, households' concerns over period-to-period rent risk are dominated by concerns over end-of-holding-period price risk, and vice versa at long horizons. $^{8}$

\section{Native Households' Behavior}

Taking the three rent levels $R_{1}, R_{H}, R_{L}$ and the price $p_{1}$ as given, a native household must choose a location and a tenure mode for period 1 , and a location plus the level of numeraire consumption for each possible state of the world in period 2. The household's housing consumption plan or location plan is denoted by the triple $\left(h_{1}, h_{H}, h_{L}\right)$, where $h_{1}, h_{H}$ and $h_{L}$ take the value of 1 for location 1 , and 0 otherwise. To indicate the tenure choice in case $h_{1}=1$, we denote the combined location-tenure plan by $\left(1_{B}, h_{H}, h_{L}\right)$ if the household buys a home, and $\left(1_{R}, h_{H}, h_{L}\right)$ if it rents one. Figure 1 summarizes the choices available to a native household.

The household has to choose among eight location plans as there are two alternatives for each of period 1 , period 2 state $H$, and period 2 state $L$. In addition, for the four location plans that involve living in location 1 in period 1 , the household must decide whether to buy or rent. That is a total of twelve location-tenure plans.

\footnotetext{
${ }^{8}$ See Sinai and Souleles (2001).
} 


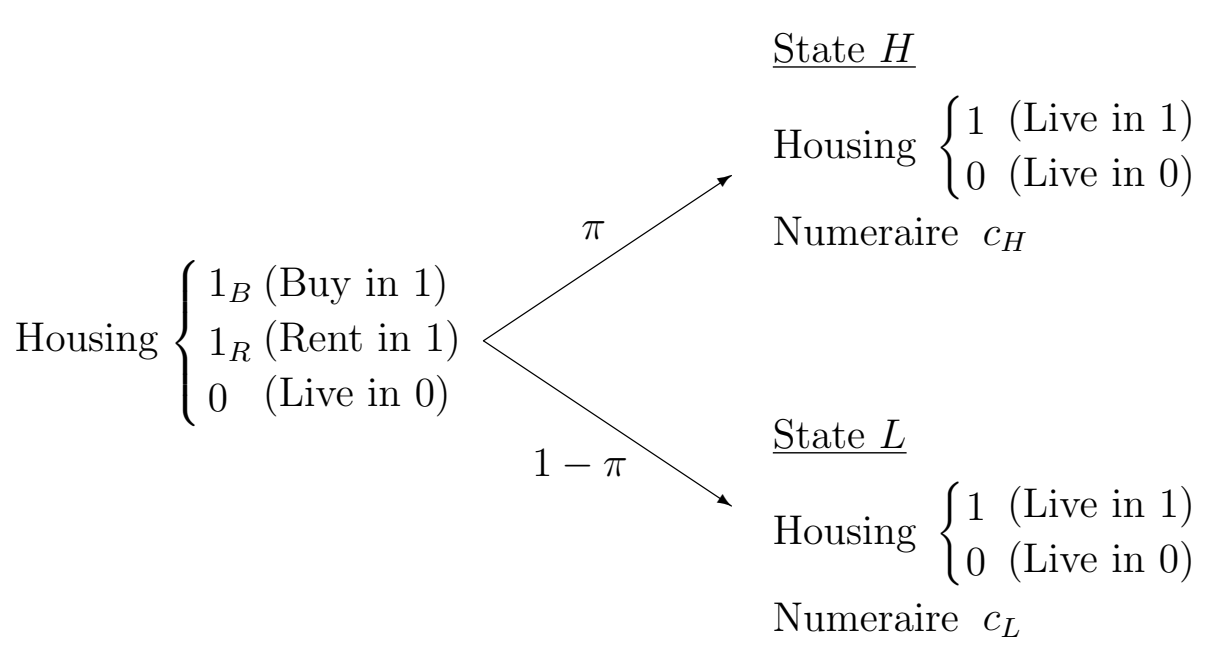

Figure 1: Household choices

\subsection{Tenure Choice}

Ex post, given that the economy is in state $s \in\{H, L\}$, given the corresponding rental price $R_{s}$, and given the household's housing and tenure choice, the budget constraint determines the consumption of the numeraire good in period 2. Hence, the household's ex-post utility is

$$
U\left(W-h_{s} R_{s}\right)+h_{s} \mu
$$

if it lived in location 0 in the first period,

$$
U\left(W-(1+r) R_{1}-h_{s} R_{s}\right)+\left(1+h_{s}\right) \mu
$$

if it rented a home in location 1 in the first period, and

$$
\begin{aligned}
& U\left(W-(1+r) p_{1}+\left(1-h_{s}\right) R_{s}\right)+\left(1+h_{s}\right) \mu \\
& \quad=U\left(W-(1+r) R_{1}-\bar{R}_{2}+\left(1-h_{s}\right) R_{s}\right)+\left(1+h_{s}\right) \mu
\end{aligned}
$$

if it bought a home in location 1 in the first period. Under this last scenario, the household pays period 1 plus expected period 2 rent and gets back the realized period 2 rent if it moves out of location 1 after the first period. 
These equations highlight what is at issue with regards to the tenure choice: the stochastic properties of numeraire consumption. For a given housing location choice, the utility derived from housing consumption is independent of tenure choice, by assumption. What the tenure determines is how shocks to housing costs translate into fluctuations in non-housing consumption. ${ }^{9}$

Equation (1) implies that expected non-housing consumption is independent of tenure choice, as can easily be seen from computing the expectation of the consumption levels figuring in (3) and (4), respectively. So the tenure choice reduces to choosing the option that induces the smallest absolute difference between the non-housing consumption levels in the two states of the economy.

In our analysis of tenure choice, we will assume that $R_{L}<R_{H}$. We will see later that this inequality must hold in any equilibrium where some newcomers choose location 1 in state $H$.

As the tenure mode in location 0 is of no consequence, we only need to consider the four housing consumption plans that involve living in location 1 in the first period: $(1,1,1),(1,1,0),(1,0,1)$, and $(1,0,0)$. It turns out that the household prefers to own if its housing consumption plan is $(1,1,1)$ or $(1,1,0)$, and prefers to rent if its plan is $(1,0,1)$ or $(1,0,0)$. The crucial difference for tenure is therefore whether or not the household plans to move out of the more desirable home in case the cost of occupying such a home turns out to be high. This is fairly obvious for the location plans with a deterministic horizon in the type 1 home, $(1,1,1)$ and $(1,0,0)$, since in these cases one of the tenure modes provides full insurance whereas the other does not. Thus, ownership dominates rental for a household who has a deterministic two-period horizon in location 1 , while the opposite holds true for a household with a deterministic one-period horizon in location 1.

Under the plans $(1,1,0)$ and $(1,0,1)$, by contrast, either tenure mode imposes some risk on the household. Under $(1,1,0)$, the household's non-housing consumption is necessarily higher in state $L$. If it rents in the first period, non-housing consumption

\footnotetext{
${ }^{9}$ In the present framework, fluctuations in non-housing consumption are entirely driven by shocks to housing costs in location 1 . If the household' earnings were stochastic, the tenure choice would depend on the extent to which rents and income co-vary, not just on the stochastic properties of the housing rent alone. Furthermore, if housing costs in location 0 were stochastic, the covariance between housing costs in the two locations would matter for tenure choice. These effects are analyzed in Ortalo-Magné and Rady (2002).
} 
in state $L$ is higher by $R_{H}$ since the second-period rent is paid precisely when it is high. If the household buys the home in the first period, on the other hand, nonhousing consumption in state $L$ is higher by $R_{L}$ since the household's non-housing consumption is boosted by the revenue from the sale of the home precisely when this revenue is low. Under $(1,1,0)$, buying is thus less risky. Under $(1,0,1)$, this logic is reversed. The household's non-housing consumption is now necessarily higher in state $H$. If it rents in the first period, non-housing consumption in state $H$ is higher by $R_{L}$ since the second-period rent is paid when it is low. If the household buys the home in the first period, on the other hand, non-housing consumption in state $H$ is higher by $R_{H}$ since the household's non-housing consumption is boosted by the revenue from the sale of the home when this revenue is high. So buying is more risky under $(1,0,1) .{ }^{10}$

We summarize these findings in

Lemma 1 If $R_{L}<R_{H}$, a native household wanting to live in location 1 in the first period prefers to own its home if and only if it plans to stay in location 1 should state $H$ occur in the second period.

\subsection{Choice of Location}

Each possible location-tenure plan determines a curve in the plane with co-ordinates $W$ (the household endowment) and $E U$ (the expected overall utility level). For any given $W$, the optimal plan is the one which yields the highest expected utility. Determining the optimal plan for every $W$ amounts to characterizing the upper envelope of these expected utility curves.

First, the CARA specification of non-housing utility implies that the expected utility of any housing consumption and tenure plan can be written as $E U=-A e^{-a W}+B$ with plan-specific constants $A>0$ and $B \geq 0$. As a consequence, if the expected utility curves of two plans cross, the curve associated with the plan that promises a

\footnotetext{
${ }^{10}$ Note that these results on tenure choice rely merely on risk aversion, and not on the CARA specification of utility. For a treatment of tenure choice with arbitrary risk averse utility of numeraire consumption, see Ortalo-Magné and Rady (2002). In the present paper, the CARA specification is adopted to make the household's choice of housing consumption plan and the computation of equilibrium tractable.
} 
larger amount of housing consumption in location 1 ex ante (and so has the higher $B$ ) is steeper at all endowment levels. ${ }^{11}$ This immediately yields

Lemma 2 The amount of housing a native household expects to consume in location 1 is weakly increasing in the household's endowment.

Second, using CARA utility, it is easy to verify that the preference ranking of the plans $\left(1_{R}, 0,0\right)$ and $(0,1,1)$ does not depend on the household's endowment $W$. In other words, the expected utility curves associated with these two plans are either identical or do not intersect.

Lemma 3 The plan $\left(1_{R}, 0,0\right)$ weakly dominates $(0,1,1)$ if and only if

$$
e^{a(1+r) R_{1}} \leq \pi e^{a R_{H}}+(1-\pi) e^{a R_{L}}
$$

with a strict preference if the inequality is strict.

Third, to make further progress in the characterization of native households' optimal housing consumption, we turn to the case where $R_{L}<R_{H}$. Under this condition, we obtain the following restriction on the set of location-tenure plans that may underlie the upper envelope of expected utility curves.

Lemma 4 If $R_{L}<R_{H}$, a native household chooses a location-tenure plan from the following subset of alternatives: $(0,0,0),(0,0,1),(0,1,1),\left(1_{R}, 0,0\right),\left(1_{R}, 0,1\right)$ and $\left(1_{B}, 1,1\right)$.

Given Lemma 1, Lemma 4 shows that two further plans are irrelevant to the household when $R_{L}<R_{H}$ : the plans $(0,1,0)$ and $\left(1_{B}, 1,0\right)$. Increasing the wealth of a household who chooses $(0,0,0)$ will prompt this household to eventually consume some housing in location 1 . The cheapest location 1 housing available is in period 2 state $L$. This is the one the household will choose first as its wealth rises. Conversely, decreasing the wealth of a household who chooses $(0,1,1)$ will prompt this household to eventually relinquish some housing in location 1 . As location 1 housing is more expensive in

\footnotetext{
${ }^{11}$ The amount of housing consumption in location 1 can be $0, \pi, 1-\pi, 1,1+\pi, 2-\pi$ or 2 .
} 
state $H$ than in state $L$, this is the one the household will give up first as its wealth decreases. This is why no household ever chooses $(0,1,0)$. The same argument applies to $\left(1_{B}, 1,0\right)$.

Fourth, continuing to assume $R_{L}<R_{H}$, we show that there exist endowment levels at which native households choose $(0,0,1)$ or $\left(1_{R}, 0,1\right)$ and so make their housing consumption in period 2 contingent on the state that occurs.

Lemma 5 Let $R_{L}<R_{H}$. Then,

(i) at least one of the plans $(0,0,1)$ and $\left(1_{R}, 0,1\right)$ is preferred to both $(0,0,0)$ and $\left(1_{B}, 1,1\right)$ at all endowment levels in some set of positive measure;

(ii) at least one of the plans $(0,0,1)$ and $\left(1_{R}, 0,0\right)$ is preferred to both $(0,0,0)$ and $\left(1_{R}, 0,1\right)$ at all endowment levels in some set of positive measure;

(iii) the plan $(0,0,1)$ is preferred to both $(0,1,1)$ and $(0,0,0)$ at all endowment levels in some set of positive measure;

(iv) the plan $\left(1_{R}, 0,1\right)$ is preferred to both $\left(1_{B}, 1,1\right)$ and $\left(1_{R}, 0,0\right)$ at all endowment levels in some set of positive measure.

This lemma is a consequence of the assumption that marginal utility of non-housing consumption decreases continuously in wealth. Together with our previous results on household behavior, it will prove useful when we characterize equilibrium prices and allocations, to which we now turn.

\section{Equilibrium}

We need to solve for the market-clearing rental costs $R_{1}, R_{H}$ and $R_{L}$ of housing in location 1 for period 1 , period 2 state $H$ and period 2 state $L$, respectively. The supply of housing in location 1 is $S$. Aggregate demand in period 1 and each state of period 2 is computed by adding up the relevant measures of households living in location 1. 
To formulate the main result of this section, we need the following definition. Let $\underline{e}>1$ be the unique real number satisfying the equality

$$
2(1-S)=W^{-1}\left(\frac{1}{a} \ln \left(\frac{\underline{e}-1}{\mu}\right)\right)+W^{-1}\left(\frac{1}{a} \ln \left(\frac{\min \left\{\underline{e}(\underline{e}-1), \mu e^{a W(1)}\right\}}{\mu}\right)\right) .
$$

Proposition 1 There is a unique equilibrium. If

$$
\mu e^{a \tilde{W}(1)}>\underline{e}-1
$$

a positive measure of newcomers choose location 1 in state $H$, the equilibrium prices satisfy $R_{L}<(1+r) R_{1}<R_{H}$ and condition (5), and the location-tenure plans chosen by a positive measure of native households are $(0,0,0),(0,0,1),\left(1_{R}, 0,0\right)$ plus either

- $(0,1,1)$, or

- $(0,1,1)$ and $\left(1_{R}, 0,1\right)$, or

- $(0,1,1),\left(1_{R}, 0,1\right)$ and $\left(1_{B}, 1,1\right)$, or

- $\left(1_{R}, 0,1\right)$ and $\left(1_{B}, 1,1\right)$.

If (7) does not hold, all newcomers choose location 0 in state $H$ and the equilibrium prices satisfy $(1+r) R_{1}=R_{L}=R_{H}=(\ln \underline{e}) / a$, so tenure does not matter. The location plans chosen by a positive measure of native households are $(0,0,0),(0,1,1),(1,0,0)$, plus possibly $(1,1,1)$.

Obviously, our interest lies in equilibria where some newcomers choose location 1 in state $H$, so that there is uncertainty about second-period housing costs. Inequality (7) provides a necessary and sufficient condition on the primitives of the model for this to be the case. This condition is straightforward to derive once one has shown that an equilibrium without any newcomers in location 1 must have $R_{H}=(\ln \underline{e}) / a$. In fact, (7) simply says that the richest among the newcomers do want to live in location 1 at this price.

In an equilibrium where some newcomers choose location 1 in state $H$, the inequality $R_{L}<R_{H}$ reflects the price pressure they exert. That the opportunity cost of choosing location 1 in the first period, $(1+r) R_{1}$, lies strictly in between $R_{L}$ and $R_{H}$ is then dictated by market clearing. Intuitively, the cost of living in location 1 in period 1 
cannot be too different from the cost of living in location 1 in period 2 for sure, a cost which lies in between $R_{L}$ and $R_{H}$.

In the remainder of this section, we sketch the main steps in the proof of Proposition 1. The detailed proof is in the appendix.

In the previous section, we derived properties of household behavior under the condition $R_{L}<R_{H}$. In the first step of the proof, we add analogs to Lemmas 4 and 5 under the conditions $R_{L}>R_{H}$ and $R_{L}=R_{H}$, respectively. This fuller description of household behavior enables us to establish that in equilibrium, $R_{L}<R_{H}$ if and only if a positive measure of newcomers choose location 1 , and $R_{L}=R_{H}$ otherwise.

In the second step, we characterize the set of possible equilibrium configurations, where by configuration we mean the set of plans that are each chosen by a positive measure of native households. This step relies on properties of household behavior plus market clearing. We proceed by first proving that all equilibrium configurations contain the plan $(0,0,0)$ under our assumption that $S<\frac{1}{2} \cdot{ }^{12}$ Then, in the case $R_{L}<R_{H}$, our assumption that $\nu<S$ implies that a positive measure of native households must choose location 1 in state $H$ and so one of the plans $\left(1_{B}, 1,1\right)$ and $(0,1,1)$. Lemma 5 together with market clearing then implies the following statements: $(1)$ if $\left(1_{B}, 1,1\right)$ is chosen, then all plans listed in Lemma 4 must be part of the configuration, possibly with the exception of $(0,1,1) ;(2)$ if $(0,1,1)$ is chosen, then the plans $(0,0,1)$ and $\left(1_{R}, 0,0\right)$ must be part of the configuration. For the case $R_{L}=R_{H}$, a simpler argument applies.

The third step of the proof consists in characterizing the households who choose the plans that make up the equilibrium configuration. By Lemma 2, this problem reduces to identifying the households who are at the margin between any two "adjacent" plans in the configuration. In preparation, we use the market clearing conditions to show that the measure of households who choose $\left(1_{R}, 0,0\right)$ is at least as large as the measure of households who choose $(0,1,1)$. By Lemma 3, this means that condition (5) holds, and with equality if $(0,1,1)$ is chosen by a positive measure of households. We therefore do not need to consider the plan $(0,1,1)$ when we compute the indices of the marginal households.

\footnotetext{
${ }^{12}$ Relaxing this assumption would add configurations without $(0,0,0)$. This would lengthen the analysis without adding any insights.
} 
Four critical endowment indices fully characterize native households' choices. For indifference between $(0,0,0)$ and $(0,0,1)$, the critical endowment index is $i_{1}$ with

$$
\mu e^{a W\left(i_{1}\right)}=\max \left\{\min \left\{e^{a R_{L}}-1, \mu e^{a W(1)}\right\}, \mu e^{a W(0)}\right\} .
$$

For indifference between $(0,0,1)$ and $\left(1_{R}, 0,0\right)$, the critical endowment index is $i_{2}$ with

$$
\mu e^{a W\left(i_{2}\right)}=\max \left\{\min \left\{\frac{e^{a(1+r) R_{1}}-\pi-(1-\pi) e^{a R_{L}}}{\pi}, \mu e^{a W(1)}\right\}, \mu e^{a W(0)}\right\} .
$$

For indifference between $\left(1_{R}, 0,0\right)$ and $\left(1_{R}, 0,1\right)$, the critical endowment index is $i_{3}$ with

$$
\mu e^{a W\left(i_{3}\right)}=\max \left\{\min \left\{e^{a(1+r) R_{1}}\left(e^{a R_{L}}-1\right), \mu e^{a W(1)}\right\}, \mu e^{a W(0)}\right\} .
$$

For indifference between $\left(1_{R}, 0,1\right)$ and $\left(1_{B}, 1,1\right)$, the critical endowment index is $i_{4}$ with

$$
\mu e^{a W\left(i_{4}\right)}=\max \left\{\min \left\{\frac{e^{a(1+r) R_{1}}\left(e^{a \bar{R}_{2}}-\pi-(1-\pi) e^{a R_{L}}\right)}{\pi}, \mu e^{a W(1)}\right\}, \mu e^{a W(0)}\right\} .
$$

Given our results on the set of possible equilibrium configurations, these critical indices satisfy the following conditions in equilibrium: $0<i_{1} \leq i_{2}<i_{3} \leq i_{4}$.

Newcomers face a deterministic one-period problem since they only enter if state $H$ occurs. Given the continuity and monotonicity of the endowment function $\tilde{W}$, we obtain a critical index $n_{1}$ such that the newcomers with index $n>n_{1}$ prefer location 1 over location 0 . This index is implicitly defined by the equation

$$
\mu e^{a \tilde{W}\left(n_{1}\right)}=\max \left\{\min \left\{e^{a R_{H}}-1, \mu e^{a \tilde{W}(1)}\right\}, \mu e^{a \tilde{W}(0)}\right\} .
$$

Figure 2 illustrates the household choices and the distribution of properties we may obtain in equilibrium. On the right of the axes the figure shows the housing consumption plan of the households whose index lies between the critical indices marked on the left of the axes. From the definition of the five critical indices, it is now trivial to compute the demand for housing in location 1 period 1, period 2 state $H$ and period 2 state $L$. Note that our use of min and max operators in the definitions of the critical indices allows us to write each demand for location 1 housing as a single expression for all possible equilibrium configurations. We obtain the following set of market clearing conditions

$$
\begin{aligned}
& S=1-i_{3}+\rho\left(i_{3}-i_{2}\right) \\
& S=1-i_{4}+(1-\rho)\left(i_{3}-i_{2}\right)+\left(1-n_{1}\right) \nu, \\
& S=1-i_{3}+(1-\rho)\left(i_{3}-i_{2}\right)+i_{2}-i_{1},
\end{aligned}
$$



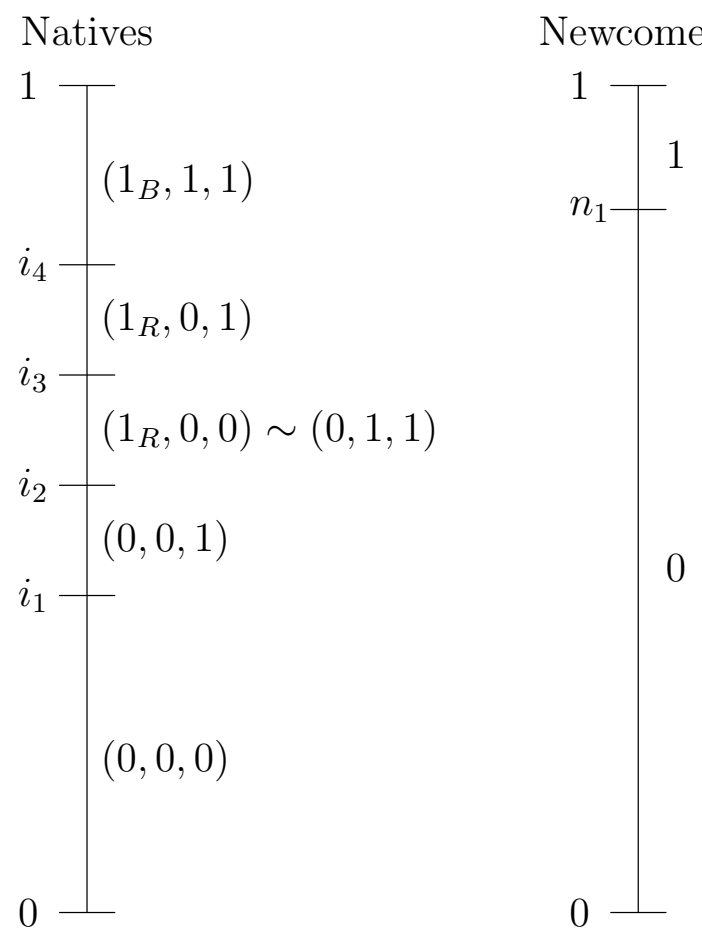

Figure 2: Possible equilibrium housing choices

where $\rho$ is the fraction of households with indices between $i_{2}$ and $i_{3}$ who choose $\left(1_{R}, 0,0\right)$. By definition, $0 \leq \rho \leq 1$. Lemma 3 implies that

$$
(1-\rho)\left(e^{a(1+r) R_{1}}-\pi e^{a R_{H}}-(1-\pi) e^{a R_{L}}\right)=0 .
$$

This system of four equations for the three rents and $\rho$ can be transformed into the following system of three equations for the three rents plus one equation for $\rho$ :

$$
\begin{aligned}
2(1-S) & =i_{1}+i_{3}, \\
2(1-S)+\nu & =i_{2}+i_{4}+\nu n_{1}, \\
e^{a(1+r) R_{1}} & =\pi \min \left\{e^{a R_{H}}, \mu e^{a W(1-S)}+1\right\}+(1-\pi) e^{a R_{L}},
\end{aligned}
$$

and

$$
\rho=\frac{i_{3}-(1-S)}{i_{3}-i_{2}} .
$$


The fourth step of the proof uses this system to establish existence and uniqueness of equilibrium and to prove that $(1+r) R_{1}$ lies between $R_{L}$ and $R_{H}$. Equations (17) and (19) determine $R_{1}$ and $R_{L}$ as monotonic functions of $R_{H}$. Equation (18) then determines a unique $R_{H}$.

\section{Comparison with a Rental-Only Economy}

We wish to contrast the results of the previous section with the equilibrium in an economy where households are not given the opportunity of owning their accommodation. So all homes have to be rented from the absentee landlords at the relevant rental price $R_{1}, R_{H}$ or $R_{L}$

Replicating the arguments we used in the economy with homeownership, we can verify that in a rental-only equilibrium where some newcomers choose location 1 in state $H$, the rental prices satisfy $R_{L}<R_{H}$ and native households will choose housing consumption plans from the following subset of alternatives: $(0,0,0),(0,0,1),(0,1,1)$, $\left(1_{R}, 0,0\right),\left(1_{R}, 0,1\right)$ and $\left(1_{R}, 1,1\right)$. Again, $(0,1,1)$ is weakly dominated by $\left(1_{R}, 0,0\right)$ and can arise as a native household's equilibrium choice only if (5) holds as an equality. So there are again four critical indices that characterize marginal households. The indices $i_{1}, i_{2}, i_{3}$ are defined exactly as in the previous section. For indifference between $\left(1_{R}, 0,1\right)$ and $\left(1_{R}, 1,1\right)$, however, the critical index is now defined by

$$
\mu e^{a W\left(i_{4}\right)}=e^{a(1+r) R_{1}}\left(e^{a R_{H}}-1\right) .
$$

Proposition 1 carries over literally to the rental-only case once the plan $\left(1_{B}, 1,1\right)$ is replaced by $\left(1_{R}, 1,1\right)$. Moreover, the necessary and sufficient condition ( 7$)$ for some newcomers to choose location 1 in state $H$ is the same in both economies. This is because tenure does not matter when all newcomers choose location 0 , so the distinction between the two economies becomes moot in this case. On the other hand, removing the plan $\left(1_{B}, 1,1\right)$ from the menu of available options only matters when some native households choose this plan in the equilibrium of the previous section. We obtain the following result. ${ }^{13}$

\footnotetext{
${ }^{13}$ We use superscripts "r" and "o" when we need to distinguish variables in the rental-only economy from their counterparts in the ownership economy.
} 
Proposition 2 There is a unique equilibrium in the rental-only economy. If a positive measure of newcomers choose location 1 in state $H$ and a positive measure of native households choose the plan $\left(1_{B}, 1,1\right)$ in the economy where homeownership is allowed, then the equilibrium prices in the rental-only economy compare as follows with those in the ownership economy:

$$
R_{1}^{r} \leq R_{1}^{o}, \quad R_{H}^{r}<R_{H}^{o}, \quad R_{L}^{r} \geq R_{L}^{o}
$$

To understand the intuition behind this result, consider the overall utility a native household gets from the plans $\left(1_{B}, 1,1\right),\left(1_{R}, 1,1\right)$ and $\left(1_{R}, 0,1\right)$ after optimizing its nonhousing consumption. Figure 3 plots these utilities against the household's endowment index, assuming the prices of the ownership equilibrium. The critical index $i_{4}$ is located where the utility curves for the housing consumption plans $\left(1_{B}, 1,1\right)$ and $\left(1_{R}, 0,1\right)$ intersect. As discussed in Section $2,\left(1_{R}, 1,1\right)$ is dominated by $\left(1_{B}, 1,1\right)$, so the utility curve of $\left(1_{R}, 1,1\right)$ lies everywhere below that of $\left(1_{B}, 1,1\right)$.

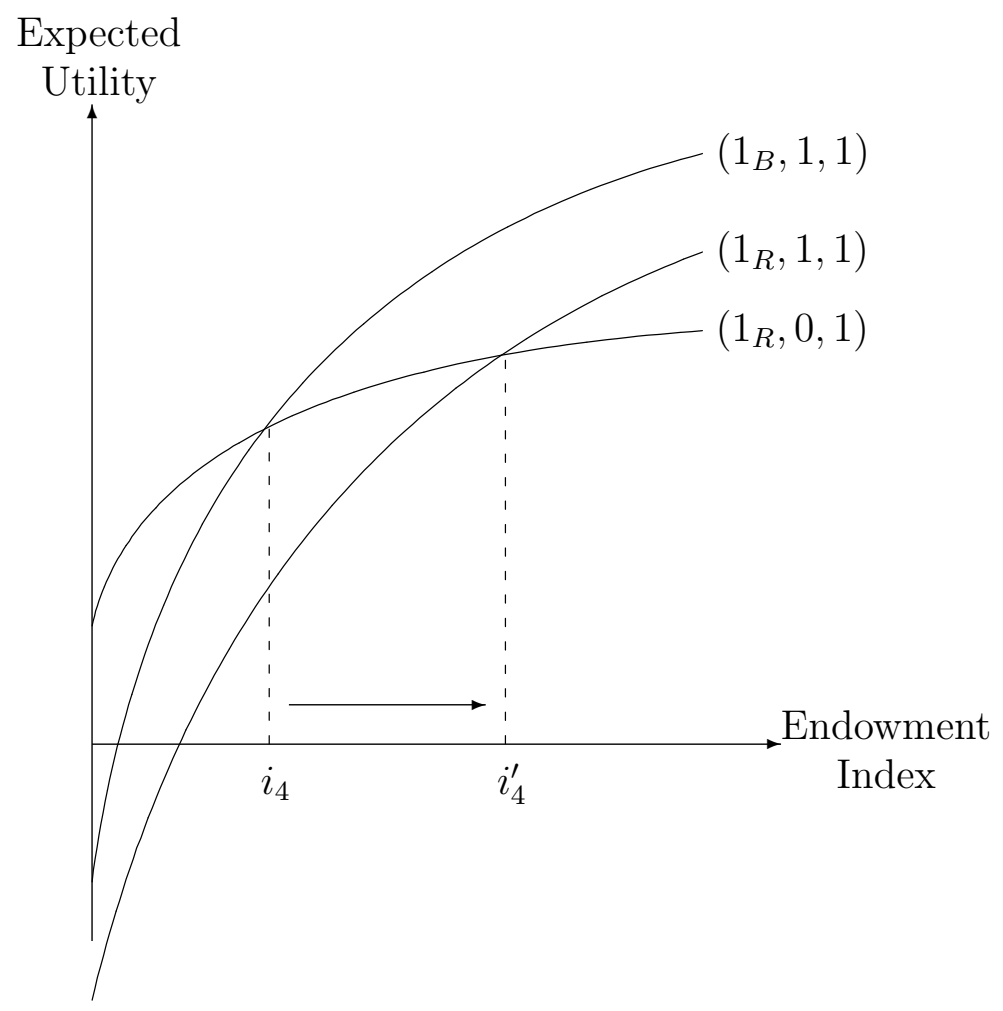

Figure 3: Comparison of the ownership and the rental-only equilibria 
Holding prices at the ownership-equilibrium level, eliminating ownership does not affect a household's utility except in the case that it plans to stay in location 1 whatever the shock. In that case, it now has to choose $\left(1_{R}, 1,1\right)$ instead of $\left(1_{B}, 1,1\right)$. Since $\left(1_{R}, 1,1\right)$ is dominated by $\left(1_{B}, 1,1\right)$, the household who used to be at the margin between $\left(1_{B}, 1,1\right)$ and $\left(1_{R}, 0,1\right)$ now prefers $\left(1_{R}, 0,1\right)$. At the prices of the ownership equilibrium, therefore, eliminating ownership causes a shift in location-tenure plans from $\left(1_{B}, 1,1\right)$ to $\left(1_{R}, 1,1\right)$ and $\left(1_{R}, 0,1\right)$. On Figure 3 , the index $i_{4}$ moves to the right, to $i_{4}^{\prime}$.

The resulting drop in demand for location 1 in state $H$ implies that the price in state $H$ must be lower in the rental economy. A lower $R_{H}$ encourages both more natives and more newcomers to choose location 1 in state $H$. Holding $R_{1}$ and $R_{L}$ constant, a lower $R_{H}$ increases the utility provided by the plan $\left(1_{R}, 1,1\right)$. On Figure 3 , this would be represented by an upward shift of the corresponding curve and a decrease in $i_{4}$. The proof of Proposition 2 establishes that this second effect on $i_{4}$ only partially compensates the increase due to the unavailability of ownership.

The lower $R_{H}$ may prompt some households who choose the plan $\left(1_{R}, 0,0\right)$ in the ownership economy to choose $(0,1,1)$ in the rental economy. If this happens, then the rents $R_{1}$ and $R_{L}$ cannot be identical in the two economies. Given the lower demand in period 1 and the higher demand in state $L$ that would result from the switch in consumption plans, $R_{1}$ must be lower and $R_{L}$ must be higher in the rental economy. If no household chooses $(0,1,1)$ in the rental economy, then the same is true in the ownership economy. ${ }^{14}$ In this case, the effect on demands in period 1 and period 2 state $L$ does not come into play, and the rents $R_{1}$ and $R_{L}$ are the same in both economies. This explains the weak inequalities for $R_{1}$ and $R_{L}$ in the proposition.

As Proposition 2 shows, allowing households to own their home affects both price dynamics and the response of the distribution of households across locations. First, allowing households to own their home increases the volatility of housing prices as measured by their second-period variance. This is an immediate consequence of the fact that the difference $R_{H}-R_{L}$ is strictly larger in the case where households are allowed to own their homes.

\footnotetext{
${ }^{14}$ This result is easy to derive from the proof of Lemma A.13 in the appendix.
} 
Second, allowing households to own their home increases the number of native households that choose to remain in location 1 in state $H$, and reduces the number of newcomer households moving in. Given how the equilibrium rental prices in the two economies compare, the newcomers' critical index $n_{1}$ is higher in the ownership economy while the natives' critical index $i_{2}$ is at least as high as in the rental-only economy. By market clearing, in particular equation (18), this implies that the native households' critical index $i_{4}$ is smaller in the ownership economy.

Third, allowing households to own their home increases the difference between the average income of the newcomers who move to location 1 and the average income of the natives who stay in location 1 in period 2 when state $H$ occurs. In fact, as $i_{4}$ is lower and $n_{1}$ is higher in the economy with homeownership, some poorer native households stay put in location 1 in state $H$ when ownership is an option, while the income distribution of the newcomers who choose location 1 is truncated at a higher level. Unless the average income of newcomers located in 1 is lower than the average income of their native neighbors, this difference in averages implies greater income dispersion under homeownership than in the rental-only economy.

We summarize these findings in the following corollary.

Corollary 1 Allowing households to own their home increases the variance of secondperiod housing prices, reduces the number of newcomer households moving to location 1 when state $H$ occurs, and increases the difference in average income between the newcomers and the natives who live in location 1 in state $H$.

Who gains from ownership, who looses? If only $R_{H}$ differs between the ownership and the rental economy, the only households affected are the ones who live in location 1 in both periods. These households benefit from ownership because it enables them to insure their second-period housing expenditures. The same effect remains if all rents differ between the ownership and the rental economy but the changes in $R_{1}$ and $R_{L}$ now affect the welfare of all households who consume some housing in location 1. Those who choose $(0,0,1)$ in both economies face a lower rent $R_{L}$ in the ownership economy and so are better off. This implies that some households who would not consume any location 1 housing in the rental economy would in case of a downturn in the ownership economy. Households who choose $\left(1_{R}, 0,0\right)$ face a higher rent in the 
ownership economy and so are worse off; the same must be true for any household who chooses $(0,1,1)$. The relative differences of $R_{1}$ and $R_{L}$ between the two economies are such that the households who choose $\left(1_{R}, 0,1\right)$ in both economies are also worse off under ownership. ${ }^{15}$

Overall, the main beneficiaries from ownership are the richest households, who take advantage of the insurance benefit of owning their home and live in location 1 for both periods. Households who choose the next lower level of housing consumption, those who move out of location 1 in case of a boom, are at best as well off in the ownership economy as in the rental economy. This is why fewer households choose to move out of location 1 in response to a boom in the ownership economy, hence our results on the contribution of homeownership to housing market dynamics.

\section{Concluding Remarks}

By providing insurance against rent increases, homeownership decreases household mobility, which in turn amplifies the volatility of housing prices and may lead to greater income dispersion within neighborhoods. These results are robust to introducing income uncertainty in addition to the labor shock we model. Households who do not expect their income to follow housing costs, yet want to remain in the desirable location, have the strongest incentive to own. In the economy with homeownership, more of them choose to stay put, so the insights gathered above remain.

Whether or not households are allowed to own their home raises primarily distributional issues. Homeownership does not generate any inefficiencies in our model of the housing market. It still remains that homeownership may amplify existing inefficiencies in the broader economy. This would be the case if efficiency in the labor market required a spatial allocation of workers driven by human capital. Given the determinant role of household wealth for the allocation of workers over space via the housing market, by disconnecting the wealth distribution from the human capital distribution, homeownership may generate or amplify labor market inefficiencies.

\footnotetext{
${ }^{15}$ This result is easy to derive from the proof of Lemma A.14 in the appendix.
} 
The model focuses on the housing market incompleteness which stems from the bundling of housing consumption and investment into the same durable good. The longer a household plans to remain in its home, the stronger its incentive to own as insurance against period-to-period rent risk. Any further incentive to own would only amplify the effects of homeownership. For example, a preference for homeownership, moral hazard in the rental market, or mortgage interest deductions would encourage more households to own their home and to stay put in the face of a local boom.

Several proposals have been put forward to eliminate the housing market incompleteness we focused on here; e.g., Case, Shiller and Weiss (1993) and Caplin et al. (1997). Housing price index derivatives and home equity insurance have recently come to life and more products are being planned. The empirical literature arguing in favor of such instruments implicitly assumes that they would not affect housing returns. The insights of the present paper suggest, however, that allowing households to disconnect their housing consumption from their housing investment will affect housing market dynamics. This will be the focus of future research. 


\section{References}

Bénabou, Roland (1993): "Workings of a City: Location, Education, and Production," Quarterly Journal of Economics, 108, 612-52.

Caplin, Andrew, Sewin Chan, Charles Freeman, and Joseph Tracy (1997): Housing Partnerships, MIT Press, Cambridge, MA.

Case, Karl E., Robert J. Shiller, and Allan N. Weiss (1993): "Index-Based Futures and Options Markets in Real Estate," Journal of Portfolio Management, 19, 83-92.

Chiuri, Maria C., and Tullio Jappelli (forthcoming): "Financial Market Imperfections and Home Ownership: A Comparative Study," European Economic Review.

Davidoff, Thomas (2001): "Labor Income, Housing Prices and Homeownership," mimeo, Dept. of Economics, MIT.

Durlauf, Steven N. (1996): "A Theory of Persistent Income Inequality," Journal of Economic Growth, 1, 75-93.

Epple, Dennis, Radu Filimon, and Thomas Romer (1984): "Equilibrium among Local Jurisdictions: Toward an Integrated Approach of Voting and Residential Choice," Journal of Public Economics, 24, 281-308.

Epple, Dennis, Radu Filimon, and Thomas Romer (1993): "Existence of Voting and Housing Equilibrium in a System of Communities with Property Taxes," Regional Science and Urban Economics, 23, 585-610.

Epple, Dennis, and Glenn J. Platt (1998): "Equilibrium and Local Redistribution in an Urban Economy when Households Differ in Both Preferences and Incomes," Journal of Urban Economics, 43, 23-51.

Epple, Dennis, and Holger Sieg (1999): "Estimating Equilibrium Models of Local Jurisdictions," Journal of Political Economy, 107, 645-681.

Goodspeed, Timothy J. (1989): "A Re-examination of the Use of Ability to Pay Taxes by Local Governments," Journal of Public Economics, 38, 319-42. 
Haavio, Markus, and Heikki Kauppi (2002): "Housing Markets, Borrowing Constraints and Labor Mobility," mimeo, Dept. of Economics, University of Helsinki.

Hilber, Christian A.L. (2002): "Neighborhood Externality Risk and the Homeownership Status of Properties," mimeo, The Wharton School, University of Pennsylvania.

Ioannides, Yannis M. (2001): "Neighborhood Income Distributions," Working Paper 2001-03, Dept. of Economics, Tufts University.

Ioannides, Yannis M., and Tracey N. Seslen (2001): "Neighborhood Wealth Distributions," Working Paper 2001-16, Dept. of Economics, Tufts University.

Linneman, P., and Susan M. Wachter (1989): "The Impacts of Borrowing Constraints on Homeownership," Journal of the American Real Estate Urban Economics Association, 17, 389-402.

Ortalo-Magné, François, and Sven Rady (1999): "Boom In, Bust Out: Young Households and the Housing Price Cycle," European Economic Review, 43, 755-66.

Ortalo-Magné, François, and Sven Rady (2002): "Tenure Choice and the Riskiness of Non-Housing Consumption," Journal of Housing Economics, 11, 266-79.

Sinai, Todd and Nicholas Souleles (2001): "Owner-Occupied Housing as a Hedge Against Rent Risk," mimeo, The Wharton School, University of Pennsylvania. 


\section{Appendix}

\section{A.1 Proofs}

To ease the notational burden, we define

$$
e_{1}=e^{a(1+) R_{1}}, \quad e_{H}=e^{a R_{H}}, \quad e_{L}=e^{a R_{L}}, \quad e_{2}=e^{a \bar{R}_{2}} .
$$

Proof of Lemma 4: In view of Lemma 1 , it is enough to show that the plans $\left(1_{B}, 1,0\right)$ and $(0,1,0)$ are never optimal. We deal with $\left(1_{B}, 1,0\right)$ first.

Suppose $\pi>\frac{1}{2}$. Let $W_{1}$ be the endowment level at which a native household would be indifferent between the plans $\left(1_{R}, 0,1\right)$ and $\left(1_{B}, 1,1\right)$, and $W_{2}$ the endowment level at which it would be indifferent between the plans $\left(1_{R}, 0,1\right)$ and $\left(1_{B}, 1,0\right)$. To show that the plan $\left(1_{B}, 1,0\right)$ is never optimal, it suffices to show that $W_{1}<W_{2}$. To see this, recall from Section 2 that if the expected utility curves of two plans cross, the curve associated with the plan that promises a larger amount of housing consumption in location 1 ex ante is steeper at all endowment levels. The curve associated with $\left(1_{B}, 1,1\right)$ is above the curve associated with $\left(1_{R}, 0,1\right)$ to the right of $W_{1}$, and the curve associated with $\left(1_{R}, 0,1\right)$ is above the curve associated with $\left(1_{B}, 1,0\right)$ to the left of $W_{2}$. If $W_{1}<W_{2}$, this implies that the curve associated with $\left(1_{B}, 1,0\right)$ is everywhere below the upper envelope of the curves associated with $\left(1_{R}, 0,1\right)$ and $\left(1_{B}, 1,1\right)$.

It is straightforward to verify that the endowment levels $W_{1}$ and $W_{2}$ are defined by

$$
\begin{aligned}
\mu e^{a W_{1}} & =\frac{1}{\pi} e_{1}\left[e_{2}-\pi-(1-\pi) e_{L}\right], \\
\mu e^{a W_{2}} & =\frac{1}{1-2 \pi} e_{1}\left[(1-\pi)\left(e_{L}-\frac{e_{2}}{e_{L}}\right)-\pi\left(e_{2}-1\right)\right] .
\end{aligned}
$$

It is easy to show that $W_{1}<W_{2}$ if and only if $e_{2}>e_{L}$, which in turn is equivalent to $R_{L}<R_{H}$.

Now suppose $\pi<\frac{1}{2}$. Let $W_{3}$ be the endowment level at which a native household would be indifferent between the plans $\left(1_{R}, 0,1\right)$ and $\left(1_{R}, 0,0\right)$ :

$$
\mu e^{a W_{3}}=e_{1}\left(e_{L}-1\right) .
$$

The plan $\left(1_{B}, 1,0\right)$ is never optimal if $W_{2}<W_{3}$. This inequality is easily seen to be equivalent to $e_{2}>e_{L}$.

In the case where $\pi=\frac{1}{2}$, a comparison of expected utilities shows that for $e_{2}>e_{L}$, the plan $\left(1_{R}, 0,1\right)$ is preferred to $\left(1_{B}, 1,0\right)$ at all endowment levels. This completes the proof that $\left(1_{B}, 1,0\right)$ is never optimal.

Turning to $(0,1,0)$, suppose $\pi>\frac{1}{2}$. Let $W_{4}$ be the endowment level at which a native household would be indifferent between the plans $(0,1,0)$ and $(0,1,1)$, and $W_{5}$ the endowment level at which it would be indifferent between the plans $(0,0,1)$ and $(0,1,0)$ :

$$
\begin{aligned}
\mu e^{a W_{4}} & =e_{L}-1, \\
\mu e^{a W_{5}} & =\frac{1-\pi}{1-2 \pi}\left(e_{L}-1\right)-\frac{\pi}{1-2 \pi}\left(e_{H}-1\right) .
\end{aligned}
$$

The plan $(0,1,0)$ is never optimal if $W_{4}<W_{5}$. It is easy to verify that this inequality is equivalent to $e_{L}<e_{H}$.

Next suppose $\pi<\frac{1}{2}$. Let $W_{6}$ be the endowment level at which a native household would be indifferent between the plans $(0,0,0)$ and $(0,0,1)$, and $W_{7}$ the endowment level at which it would be indifferent between the plans $(0,0,0)$ and $(0,1,0)$ :

$$
\begin{aligned}
& \mu e^{a W_{6}}=e_{L}-1, \\
& \mu e^{a W_{7}}=e_{H}-1 .
\end{aligned}
$$


The plan $(0,1,0)$ is never optimal if $W_{6}<W_{7}$, which is obviously the same as $e_{L}<e_{H}$.

In the case where $\pi=\frac{1}{2}$, a comparison of expected utilities shows that for $e_{L}<e_{H}$, the plan $(0,0,1)$ is preferred to $(0,1,0)$ at all endowment levels. This completes the proof.

Proof of Lemma 5: Part (i): Let $W_{1}$ be the endowment level at which a native household would be indifferent between the plans $(0,0,0)$ and $\left(1_{R}, 0,1\right)$, and $W_{2}$ the endowment level at which it would be indifferent between the plans $\left(1_{R}, 0,1\right)$ and $\left(1_{B}, 1,1\right)$. To show that the plan $\left(1_{R}, 0,1\right)$ is preferred to both $(0,0,0)$ and $\left(1_{B}, 1,1\right)$ on a set of endowment levels of positive measure, it is enough to show that $W_{1}<W_{2}$. To see this, recall from Section 2 that if the expected utility curves of two plans cross, the curve associated with the plan that promises a larger amount of housing consumption in location 1 ex ante is steeper at all endowment levels. The curve associated with $\left(1_{R}, 0,1\right)$ is above the curve associated with $(0,0,0)$ to the right of $W_{1}$, and above the curve associated with $\left(1_{B}, 1,1\right)$ to the left of $W_{2}$. If $W_{1}<W_{2}$, therefore, $\left(1_{R}, 0,1\right)$ is preferred to both $(0,0,0)$ and $\left(1_{B}, 1,1\right)$ at all wealth levels strictly between $W_{1}$ and $W_{2}$. It is straightforward to verify that the endowment levels $W_{1}$ and $W_{2}$ are defined by

$$
\begin{aligned}
\mu e^{a W_{1}} & =\frac{1}{2-\pi}\left[\pi e_{1}+(1-\pi) e_{1} e_{L}-1\right] \\
\mu e^{a W_{2}} & =\frac{e_{1}}{\pi}\left[e_{2}-\pi-(1-\pi) e_{L}\right]
\end{aligned}
$$

It is easy to see that $W_{1}<W_{2}$ if and only of $2(1-\pi) e_{1}\left(e_{2}-e_{L}\right)+\pi\left[e_{1} e_{2}-2 e_{1}+1\right]>0$. As $e_{L}<e_{H}$, we have $e_{2}>e_{L}$. If $e_{2} \geq e_{1}$, we also have $e_{1} e_{2}-2 e_{1}+1 \geq\left(e_{1}-1\right)^{2}$, so $e_{2} \geq e_{1}$ is a sufficient condition for $W_{1}<W_{2}$, and hence for $\left(1_{R}, 0,1\right)$ to be preferred to $(0,0,0)$ and $\left(1_{B}, 1,1\right)$ on some open interval of endowment levels.

Next, let $W_{3}$ be the endowment level at which a native household would be indifferent between the plans $(0,0,0)$ and $(0,0,1)$, and $W_{4}$ the endowment level at which it would be indifferent between the plans $(0,0,0)$ and $\left(1_{B}, 1,1\right)$ :

$$
\begin{aligned}
\mu e^{a W_{3}} & =e_{L}-1 \\
\mu e^{a W_{4}} & =\frac{1}{2-\pi}\left[e_{1} e_{2}-\pi-(1-\pi) e_{L}\right] .
\end{aligned}
$$

It is easy to see that $W_{3}<W_{4}$ if and only of $e_{1} e_{2}-2 e_{2}+1+2\left(e_{2}-e_{L}\right)>0$. As $e_{L}<e_{H}$, we have $e_{2}>e_{L}$. If $e_{1} \geq e_{2}$, we also have $e_{1} e_{2}-2 e_{2}+1 \geq\left(e_{2}-1\right)^{2}$, so $e_{1} \geq e_{2}$ is a sufficient condition for $W_{3}<W_{4}$, and hence for $(0,0,1)$ to be preferred to $(0,0,0)$ and $\left(1_{B}, 1,1\right)$ on some open interval of endowment levels.

Part (ii): An argument similar to the one used for part (i) shows first that for $e_{1} \leq e_{L},\left(1_{R}, 0,0\right)$ is preferred to $(0,0,0)$ and $\left(1_{R}, 0,1\right)$ on some open interval of endowment levels; and second, that for $e_{1} \geq e_{L},(0,0,1)$ is preferred to $(0,0,0)$ and $\left(1_{R}, 0,1\right)$ on some open interval of endowment levels.

Part (iii): Let $W_{5}$ be the endowment level at which a native household would be indifferent between the plans $(0,0,0)$ and $(0,1,1)$, and $W_{6}$ the endowment level at which it would be indifferent between the plans $(0,0,1)$ and $(0,1,1)$ :

$$
\begin{aligned}
\mu e^{a W_{5}} & =\pi e_{H}+(1-\pi) e_{L}-1 \\
\mu e^{a W_{6}} & =e_{H}-1
\end{aligned}
$$

It suffices to show that $W_{5}<W_{6}$. This is easily seen to be equivalent to $e_{L}<e_{H}$.

Part (iv): Let $W_{7}$ be the endowment level at which a native household would be indifferent between the plans $\left(1_{R}, 0,0\right)$ and $\left(1_{B}, 1,1\right)$, and $W_{8}$ the endowment level at which it would be indifferent between the plans $\left(1_{R}, 0,1\right)$ and $\left(1_{B}, 1,1\right)$ :

$$
\begin{aligned}
\mu e^{a W_{7}} & =e_{1}\left(e_{2}-1\right), \\
\mu e^{a W_{8}} & =e_{1}\left[e_{2}-1+\frac{1-\pi}{\pi}\left(e_{2}-e_{1}\right)\right] .
\end{aligned}
$$


It suffices to show that $W_{7}<W_{8}$. This is easily seen to be equivalent to $e_{L}<e_{2}$, which in turn is the same as $e_{L}<e_{H}$.

Proof of Proposition 1: Lemma A.6 shows that in equilibrium, second period rents satisfy $R_{L}<R_{H}$ if a positive measure of newcomers choose location 1 , and $R_{L}=R_{H}$ otherwise. Lemma A.11 shows that (5) holds if $R_{L}<R_{H}$. Lemmas A.8 and A.9 show that equilibrium configurations must be as stated in the proposition. This implies that the relevant market clearing conditions are (13)-(16). Lemma A.12 shows that these conditions are equivalent to the system of equations (17)(20). Lemmas A.13 and A.14 show that this system admits a unique solution with $R_{L} \leq R_{H}$ and the properties stated in the proposition. Lemma A.15 shows that this solution yields an equilibrium.

Proof of Proposition 2: Existence and uniqueness of equilibrium are shown along exactly the same lines as in the proof of Proposition 1. Note in particular that equations (17) and (19) are the same in both economies, so Lemma A.13 with its description of $e_{1}$ and $e_{L}$ as continuous monotonic functions of $e_{H}$ carries over without any modification. Given a value for $e_{H}$, we thus have the same values for $e_{1}, e_{L}, i_{2}$ and $n_{1}$ in both economies. In contrast, we have $i_{4}^{o}<i_{4}^{r}$ at any given value of $e_{H}$ that is assumed common to both economies, different from $e_{L}$ and such that $0<i_{4}^{o}<1$. By the definitions of these indices, the stated inequality is equivalent to $e_{2}-(1-\pi) e_{L}<\pi e_{H}$, which always holds by the convexity of the exponential function. As a function of $e_{H}$, therefore, the right-hand side of (18) is strictly larger in the rental-only economy over the range where $0<i_{4}^{o}<1$. This implies that if $i_{4}^{o}<1$ in the ownership equilibrium, then the equilibrium rental prices in state $H$ satisfy $e_{L}<e_{H}$. The remaining comparison results now follow from Lemma A.13.

\section{A.2 Auxiliary Results on Household Behavior}

If $R_{L}>R_{H}$, the roles of the two states in period 2 are reversed. The following three results are therefore just mirror images of Lemmas 1, 4 and 5, respectively, and do not require proofs of their own.

Lemma A.1 If $R_{L}>R_{H}$, a native household wanting to live in location 1 in the first period prefers to own its home if and only if it plans to stay in location 1 should state $L$ occur in the second period.

Lemma A.2 If $R_{L}>R_{H}$, a native household chooses a location-tenure plan from the following subset of available options: $(0,0,0),(0,1,0),(0,1,1),\left(1_{R}, 0,0\right),\left(1_{R}, 1,0\right)$ and $\left(1_{B}, 1,1\right)$.

Lemma A.3 Let $R_{L}>R_{H}$. Then:

(i) at least one of the plans $(0,1,0)$ and $\left(1_{R}, 1,0\right)$ is preferred to both $(0,0,0)$ and $\left(1_{B}, 1,1\right)$ at all endowment levels in some set of positive measure;

(ii) at least one of the plans $(0,1,0)$ and $\left(1_{R}, 0,0\right)$ is preferred to both $(0,0,0)$ and $\left(1_{R}, 1,0\right)$ at all endowment levels in some set of positive measure;

(iii) the plan $(0,1,0)$ is preferred to both $(0,1,1)$ and $(0,0,0)$ at all endowment levels in some set of positive measure;

(iv) the plan $\left(1_{R}, 1,0\right)$ is preferred to both $\left(1_{B}, 1,1\right)$ and $\left(1_{R}, 0,0\right)$ at all endowment levels in some set of positive measure.

If $R_{H}=R_{L}$, the tenure mode is irrelevant, so native households' decisions concern location only.

Lemma A.4 If $R_{L}=R_{H}$, each of the location plans $(1,1,0),(1,0,1),(0,1,0)$ and $(0,0,1)$ is optimal for a native household at precisely one endowment level, and suboptimal at all other endowment levels. Thus, only the plans $(0,0,0),(0,1,1),(1,0,0)$ and $(1,1,1)$ may be chosen by a positive measure of native households. 
Proof: The first statement follows if we let $R_{L}$ tend to $R_{H}$ in Lemmas 4 and A.2. The second statement follows trivially from the first.

Lemma A.5 Let $R_{L}=R_{H}$. If the location plans $(1,1,1)$ and $(0,0,0)$ are optimal at some endowment levels, then one of the plans $(1,0,0)$ and $(0,1,1)$ is preferred to both $(1,1,1)$ and $(0,0,0)$ on a set of endowment levels of positive measure.

Proof: As $R_{L}=R_{H}$, we have $e_{L}=e_{H}=e_{2}$, for which we shall write $e_{*}$.

Let $W_{1}$ be the endowment level at which a native household would be indifferent between the plans $(0,0,0)$ and $(1,0,0)$, and $W_{2}$ the endowment level at which it would be indifferent between the plans $(1,0,0)$ and $(1,1,1)$ :

$$
\begin{aligned}
& \mu e^{a W_{1}}=e_{1}-1, \\
& \mu e^{a W_{2}}=e_{1}\left(e_{*}-1\right) .
\end{aligned}
$$

Thus, $W_{1}<W_{2}$ if and only if $e_{1}\left(e_{*}-e_{1}\right)+\left(e_{1}-1\right)^{2}>0$, a sufficient condition for which is $e_{*} \geq e_{1}$.

Next, let $W_{3}$ be the endowment level at which a native household would be indifferent between the plans $(0,0,0)$ and $(0,1,1)$, and $W_{4}$ the endowment level at which it would be indifferent between the plans $(0,1,1)$ and $\left(1_{B}, 1,1\right)$ :

$$
\begin{aligned}
\mu e^{a W_{3}} & =e_{*}-1 \\
\mu e^{a W_{4}} & =e_{*}\left(e_{1}-e_{*}\right) .
\end{aligned}
$$

Thus, $W_{3}<W_{4}$ if and only if $e_{*}\left(e_{1}-e_{*}\right)+\left(e_{*}-1\right)^{2}>0$, a sufficient condition for which is $e_{1} \geq e_{*}$. This implies that no matter what $e_{1}$ and $e_{*}$ are, at least one of the inequalities $W_{1}<W_{2}$ and $W_{3}<W_{4}$ holds.

\section{A.3 Results on Equilibrium Prices and Configurations}

In the following, we shall write $D_{1}, D_{H}$ and $D_{L}$ for native households' aggregate demand for housing in location 1 in period 1 , period 2 state $H$, and period 2 state $L$, respectively.

Lemma A.6 In equilibrium, second period rents satisfy $R_{L}<R_{H}$ if a positive measure of newcomers choose location 1, and $R_{L}=R_{H}$ otherwise.

Proof: Suppose that $R_{L} \geq R_{H}$ with a positive measure of newcomers choosing location 1 in state $H$. Then, Lemmas A.2 and A.4 imply that $D_{L} \leq D_{H}$. Aggregate demand for housing in location 1 by native households and newcomers is therefore higher in state $H$ than in state $L$. Given that the supply of housing in location 1 is the same in both states, this is incompatible with market clearing. This proves the first part of the lemma.

Next, suppose that $R_{L}<R_{H}$ with all newcomers choosing location 0 in state $H$. Then, market clearing implies $D_{H}=D_{L}$, which in turn implies that the plans $\left(1_{R}, 0,1\right)$ and $(0,0,1)$ are not chosen by any native households. This contradicts parts (ii) and (iii) of Lemma 5 unless either $\left(1_{R}, 0,0\right)$ and $(0,1,1)$ are the only plans chosen (in which case they are chosen in equal measure), or $\left(1_{B}, 1,1\right)$ and $(0,0,0)$ are the only plans chosen. The first alternative contradicts our assumption that $S<\frac{1}{2}$, the second contradicts part (i) of Lemma 5. A similar argument involving Lemma A.3 instead of Lemma 5 shows that the inequality $R_{L}>R_{H}$ is incompatible with no newcomers choosing location 1 in state $H$. This proves the second part of the lemma.

Lemma A.7 In any equilibrium, the plan $(0,0,0)$ is chosen by a positive measure of native households. 
Proof: From Lemma A.6, we know that $R_{L} \leq R_{H}$. From Lemmas 4 and A.4, we know that the only housing consumption plans that may be chosen by a positive measure of native households are $(1,1,1),(1,0,1),(1,0,0),(0,1,1),(0,0,1)$ and $(0,0,0)$. We write $m_{111}$ for the measure of native households choosing $(1,1,1), m_{101}$ for the measure of native households choosing $(1,0,1)$ etc.

Now suppose $m_{000}=0$. Then, market clearing in period 1 implies $m_{001}+m_{011}=1-S$; market clearing in period 2 state $L$ implies $m_{100}=1-S$. Adding up these two equations yields $m_{001}+m_{011}+$ $m_{100}=2(1-S)>1$, which contradicts the fact that the total native population has size 1 .

Lemma A.8 In an equilibrium where a positive measure of newcomers choose location 1 in state $H$, the location-tenure plans chosen by a positive measure of native households are $(0,0,0),(0,0,1)$, $\left(1_{R}, 0,0\right)$ plus either

(a) $(0,1,1)$, or

(b) $(0,1,1)$ and $\left(1_{R}, 0,1\right)$, or

(c) $(0,1,1),\left(1_{R}, 0,1\right)$ and $\left(1_{B}, 1,1\right)$, or

(d) $\left(1_{R}, 0,1\right)$ and $\left(1_{B}, 1,1\right)$.

Proof: From Lemma A.6, we know that $R_{L}<R_{H}$. From Lemma 4, we know that the only plans that may be chosen by a positive measure of native households are $\left(1_{B}, 1,1\right),\left(1_{R}, 0,1\right),(0,1,1),\left(1_{R}, 0,0\right)$, $(0,0,1)$ and $(0,0,0)$. Because of our assumption that $\nu<S$, there must be a positive measure of native households consuming housing in location 1 in state $H$. This means that at least one of the plans $\left(1_{B}, 1,1\right)$ and $(0,1,1)$ must be chosen. ${ }^{16}$

Case 1: $(0,1,1)$ is not chosen, so $\left(1_{B}, 1,1\right)$ must be chosen. We want to show that $\left(1_{R}, 0,1\right)$, $\left(1_{R}, 0,0\right)$ and $(0,0,1)$ are chosen as well. Market clearing requires $D_{1}=D_{L}>D_{H}$, so $\left(1_{R}, 0,1\right)$ must be chosen, or both $\left(1_{R}, 0,0\right)$ and $(0,0,1)$ must be chosen. By part (iv) of Lemma $5,\left(1_{R}, 0,1\right)$ is chosen whenever $\left(1_{R}, 0,0\right)$ is chosen. So $\left(1_{R}, 0,1\right)$ must be chosen. Next, Lemma A.7 implies that $(0,0,0)$ is chosen, so by part (ii) of Lemma 5 , at least one of $(0,0,1)$ and $\left(1_{R}, 0,0\right)$ is chosen. As $D_{1}=D_{L}$, one cannot be chosen without the other.

Case 2: $\left(1_{B}, 1,1\right)$ is not chosen, so $(0,1,1)$ must be chosen. First, note that $\left(1_{R}, 0,0\right)$ must be chosen as well; otherwise, $D_{1}$ cannot equal $D_{L}$. Next, Lemma A.7 implies that $(0,0,0)$ is chosen, so by part (iii) of Lemma $5,(0,0,1)$ is chosen.

Case 3: Both $\left(1_{B}, 1,1\right)$ and $(0,1,1)$ are chosen. Arguing as in the previous case, we see that $\left(1_{R}, 0,0\right)(0,0,1)$ and $(0,0,0)$ are chosen as well. Finally, part (iv) of Lemma 5 implies that $\left(1_{R}, 0,1\right)$ is also chosen.

Lemma A.9 In an equilibrium where all newcomers choose location 0 in state $H$, the location plans chosen by a positive measure of native households are $(0,0,0),(0,1,1),(1,0,0)$ plus possibly $(1,1,1)$.

Proof: From Lemma A.6, we know that $R_{L}=R_{H}$. For this case, Lemma A.4 implies that the only housing consumption plans possibly chosen by a positive measure of native households in equilibrium are $(0,0,0),(0,1,1),(1,0,0)$ and $(1,1,1)$. Lemma A.7 implies that $(0,0,0)$ is chosen. Lemma A.5 implies that the configuration cannot just consist of $(0,0,0)$ and $(1,1,1)$. Market clearing implies that if the equilibrium configuration contains $(0,1,1)$, it must also contain $(1,0,0)$, and vice versa.

By Lemma 3, this immediately implies

Lemma A.10 In an equilibrium where all newcomers choose location 0 in state $H$, equation (5) holds with equality; as $R_{L}=R_{H}$, this means $(1+r) R_{1}=R_{L}=R_{H}$.

\footnotetext{
${ }^{16}$ Here and in what follows, we always understand the word "chosen" to mean "chosen by a positive measure of native households".
} 
Lemma A.11 In an equilibrium where a positive measure of newcomers choose location 1 in state $H$, the measure of native households who choose the plan $\left(1_{R}, 0,0\right)$ is at least as large as the measure of native households who choose the plan $(0,1,1)$. As a consequence, $(0,1,1)$ cannot dominate $\left(1_{R}, 0,0\right)$, so (5) holds.

Proof: Suppose to the contrary that fewer native households choose $\left(1_{R}, 0,0\right)$ than $(0,1,1)$. In view of Lemmas A.6 and 4, this implies that $D_{H} \geq D_{L}$, which is incompatible with the premise that a positive measure of newcomers choose location 1 in state $H$.

\section{A.4 Existence and Uniqueness of Equilibrium}

It will be convenient to work with $e_{1}, e_{L}$ and $e_{H}$ instead of $R_{1}, R_{L}$ and $R_{H}$, respectively. We define $\psi=\mu e^{a W(1-S)}+1$.

Lemma A.12 The system of equations (13)-(16) is equivalent to the system of equations (17)-(20).

Proof: Adding up equations (13) and (14), we obtain (18). Adding up equations (13) and (15), we obtain (17). Now, if $e_{1}<\pi e_{H}+(1-\pi) e_{L}$ then $\rho=1$. Equation (13) then implies $i_{2}=1-S$, which by the definition of $i_{2}$ yields

$$
e_{1}=\pi \psi+(1-\pi) e_{L}<\pi e_{H}+(1-\pi) e_{L} .
$$

Then, since $i_{2}=1-S$, equation (20) simply becomes $\rho=1$. If $e_{1}=\pi e_{H}+(1-\pi) e_{L}$ then $\rho \leq 1$ and the definition of $i_{2}$ becomes $\mu e^{a W\left(i_{2}\right)}=e_{H}-1$. Moreover, (13) implies $i_{2} \leq 1-S$, hence $\mu e^{a W(1-S)} \geq e_{H}-1$. Therefore,

$$
e_{1}=\pi e_{H}+(1-\pi) e_{L} \leq \pi \psi+(1-\pi) e_{L} .
$$

Therefore equation (19) holds. Using (13), we obtain (20).

Conversely, equation (19) gives us two possible cases. First, if $\mu e^{a W(1-S)}+1<e_{H}$, then (19) plus the definition of $i_{2}$ imply $i_{2}=1-S$, which yields $\rho=1$ by equation (20) and implies that equations (13) and (16) hold. Then, replacing one term $1-S$ by $i_{2}$ in equations (18) and (17) yields equations (14) and (15) for the case $\rho=1$. Second, if $\psi \leq e_{H}$, then (19) implies that (16) holds. Using (20) to replace one $1-S$ term in equations (18) and (17) yields equations (14) and (15). Rearranging (20) yields (13).

For our next result, recall the definition of $\underline{e}$ in Section 3. It is straightforward to see that $\underline{e}<\psi$.

Lemma A.13 Equations (17) and (19) yield $e_{1}$ and $e_{L}$ as continuous monotonic functions of $e_{H}$, with the first weakly increasing and the second weakly decreasing in $e_{H}$. The inequality $e_{L}<e_{H}$ holds if and only if $e_{H}>\underline{e}$. More precisely, $\mu e^{a W(1-2 S)}+1<e_{L}<\underline{e}<e_{1}<e_{H}$ if $\underline{e}<e_{H}<\psi$, and $\mu e^{a W(1-2 S)}+1<e_{L}<e_{1}<\psi \leq e_{H}$ if $e_{H} \geq \psi$. Finally, $e_{L}=e_{1}=e_{H}$ if and only if $e_{H}=\underline{e}$.

Proof: Equation (17) implies that neither $i_{1}$ nor $i_{3}$ can be zero, and at most of them can assume the value one. By the definitions of $i_{1}$ and $i_{3}$, the right-hand side of (17) is strictly increasing in $e_{L}$, and weakly increasing in $e_{1}$. This defines $e_{L}$ as a weakly decreasing function of $e_{1}$ which assumes the value $\psi$ at $e_{1}=1$ and tends to $\mu e^{a W(1-2 S)}+1$ as $e_{1}$ goes to infinity. Rearranging equation (19) into

$$
(1-\pi) e_{L}=e_{1}-\pi \min \left\{e_{H}, \psi\right\}
$$

defines $e_{L}$ as a strictly increasing function of $e_{1}$, given $e_{H}$. This function assumes a value of at most 1 at $e_{1}=1$ and tends to infinity as $e_{1}$ does. This implies that for any given $e_{H},(17)$ and (19) determine unique values of $e_{1}$ and $e_{L}$ with $\mu e^{a W(1-2 S)}+1<e_{L}<\psi$. An increase in $e_{H}$ either leaves both 
functions unchanged, or shifts the second function down and leaves the first unchanged. Continuity is obvious.

Next, note that in the $\left(e_{1}, e_{L}\right)$-plane, the graph of the function defined by (A.23) cuts the 45 degree line from below at $e_{1}=\min \left\{e_{H}, \psi\right\}$, while the graph of the function defined by (17) cuts the 45 degree line from above at $e_{1}=\underline{e}$. Using these facts, it is now easy to verify the statements about the ranking of $e_{1}, e_{H}$ and $e_{L}$.

Lemma A.14 The system of equations (17)-(19) has a unique solution with $e_{H} \geq \underline{e}$, and $e_{H}=\underline{e}$ if and only if $\mu e^{a \tilde{W}(1)} \leq \underline{e}-1$.

Proof: We want to to establish that equation (18) admits a unique solution $e_{H}$ once $e_{1}$ and $e_{L}$ are solved for as functions of $e_{H}$ according to Lemma A.13. First, we note that $i_{2}$ is weakly increasing in $e_{1}$ and weakly decreasing in $e_{L}$. This implies that $i_{2}$ is weakly increasing in $e_{H}$. Second, $n_{1}$ is also weakly increasing in $e_{H}$. Third, the definition of $i_{4}$ can be rearranged into

$$
\mu e^{a W\left(i_{4}\right)}=\max \left\{\min \left\{e_{1} e_{L}-e_{1}+e_{1} e_{L} z, \mu e^{a W(1)}\right\}, \mu e^{a W(0)}\right\},
$$

where $z=\left[\left(e_{H} / e_{L}\right)^{\pi}-1\right] / \pi$ is strictly increasing in $e_{H}$ and non-negative when $e_{H} \geq \underline{e}$. We know from the proof of Lemma A.13 that $i_{3}>0$. If $i_{3}<1$, then $\mu e^{a W\left(i_{3}\right)}=e_{1} e_{L}-e_{1}$, which is weakly increasing in $e_{H}$ by Lemma A.13 and equation (17) because $i_{1}$ is weakly decreasing in $e_{H}$. This in turn implies that $e_{1} e_{L}-e_{1}$ is weakly increasing in $e_{H}$. Given that $e_{1}$ is weakly increasing in $e_{H}, e_{1} e_{L}$ is weakly increasing. So, if $i_{3}<1$, then $i_{4}$ is weakly increasing in $e_{H}$, and strictly increasing up to the level 1 . If $i_{3}=1$, it is immediate that $i_{4}=1$ as well. This establishes that the right-hand side of (18) is strictly increasing in $e_{H}$ up to a point and then possibly constant. The term $i_{4}+\nu n_{1}$ becomes constant when $e_{H}$ is so high that $i_{4}=n_{1}=1$. In addition, when $e_{H} \geq \psi$, then equation (19) and the definition of $i_{2}$ implies that $i_{2}=1-S$. So, if the right-hand side of (18) ever becomes flat as $e_{H}$ increases, it does so at the level $2-S+\nu$ which is greater than the left-hand side of (18). At $e_{H}=\underline{e}$, we have $i_{2}=i_{1}$ and $i_{4}=i_{3}$, so (17) implies that the right-hand side of (18) does not exceed the left-hand side. This establishes existence and uniqueness of a solution to the system of equations (17)-(19) with $e_{H} \geq \underline{e}$. It also shows that $e_{H}=\underline{e}$ if and only if $n_{1}$ equals 1 at $e_{H}=\underline{e}$, that is, if and only if $\mu e^{a \tilde{W}(1)} \leq \underline{e}-1$.

Lemma A.15 The solution to the system of equations (17)-(19) identified in Lemma A.14 constitutes an equilibrium.

Proof: If $\mu e^{a \tilde{W}(1)} \leq \underline{e}-1$, we have $e_{1}=e_{L}=e_{H}=\underline{e}$ by Lemma A.13 and so $0<i_{1}=i_{2}<i_{3}=i_{4}$. If $\mu e^{a \tilde{W}(1)}>\underline{e}-1$, Lemma A.13 implies that $0<i_{1}<i_{2}<i_{3} \leq i_{4}$. This shows that the ranking of the critical endowment indices $i_{1}$ through $i_{4}$ is the one that we assumed when formulating the market clearing conditions (13)-(16). So, the solution we identified constitutes an equilibrium. 


\section{CESifo Working Paper Series}

(for full list see www.cesifo.de)

756 Jan K. Brueckner, Internalization of Airport Congestion: A Network Analysis, July 2002

757 Lawrence M. Kahn, The Impact of Wage-Setting Institutions on the Incidence of Public Employment in the OECD: 1960-98, July 2002

758 Sijbren Cnossen, Tax Policy in the European Union, August 2002

759 Chandima Mendis, External Shocks and Banking Crises in Developing Countries: Does the Exchange Rate Regime Matter?, August 2002

760 Bruno S. Frey and Lars P. Feld, Deterrence and Morale in Taxation: An Empirical Analysis, August 2002

761 Lars Calmfors and Åsa Johansson, Nominal Wage Flexibility, Wage Indexation and Monetary Union, August 2002

762 Alexander R. W. Robson and Stergios Skaperdas, Costly Enforcement of Property Rights and the Coase Theorem, August 2002

763 Horst Raff, Preferential Trade Agreements and Tax Competition for Foreign Direct Investment, August 2002

764 Alex Cukierman and V. Anton Muscatelli, Do Central Banks have Precautionary Demands for Expansions and for Price Stability? - Theory and Evidence, August 2002

765 Giovanni Peri, Knowledge Flows and Knowledge Externalities, August 2002

766 Daniel Friedman and Nirvikar Singh, Equilibrium Vengeance, August 2002

767 Sam Bucovetsky and Michael Smart, The Efficiency Consequences of Local Revenue Equalization: Tax Competition and Tax Distortions, August 2002

768 Tapio Palokangas, International Labour Market Regulation and Economic Growth with Creative Destruction, August 2002

769 Rudi Dornbusch, The New International Architecture, September 2002

770 Hans-Werner Sinn, Weber's Law and the Biological Evolution of Risk Preferences: The Selective Dominance of the Logarithmic Utility Function, September 2002

771 Thomas Mayer, The Macroeconomic Loss Function: A Critical Note, September 2002

772 Seppo Honkapohja and Kaushik Mitra, Learning Stability in Economies with Heterogenous Agents, September 2002 
773 David Laidler, Inflation Targets Versus International Monetary Integration - A Canadian Perspective, September 2002

774 Morten I. Lau, Panu Poutvaara, and Andreas Wagener, The Dynamic Cost of the Draft, September 2002

775 Steven Brakman, Harry Garretsen, and Charles van Marrewijk, Locational Competition and Agglomeration: The Role of Government Spending, September 2002

776 Anke S. Kessler and Christoph Lülfesmann, The Theory of Human Capital Revisited: On the Interaction of General and Specific Investments, September 2002

777 Kjell Erik Lommerud, Frode Meland and Lars Sørgard, Unionized Oligopoly, Trade Liberalization and Location Choice, September 2002

778 Antonio Merlo and François Ortalo-Magné, Bargaining over Residential Real Estate: Evidence from England, September 2002

779 Yu-Fu Chen and Michael Funke, Exchange Rate Uncertainty and Labour Market Adjustment under Fixed and Flexible Exchange Rates, September 2002

780 Michael S. Michael, International Migration, Income Taxes and Transfers: A Welfare Analysis, September 2002

781 Clemens Fuest and Alfons Weichenrieder, Tax Competition and Profit Shifting: On the Relationship between Personal and Corporate Tax Rates, October 2002

782 Jan Bouckaert and Hans Degryse, Softening Competition by Enhancing Entry: An Example from the Banking Industry, October 2002

783 Johann K. Brunner and Susanne Pech, Adverse Selection in the Annuity Market with Sequential and Simultaneous Insurance Demand, October 2002

784 Gregory D. Hess and Eduard Pelz, The Economic Welfare Cost of Conflict: An Empirical Assessment, October 2002

785 Jan Erik Askildsen, Uwe Jirjahn, and Stephen C. Smith, Works Councils and Environmental Investment: Theory and Evidence from German Panel Data, October 2002

786 Geir H. Bjønnes, Dagfinn Rime, and Haakon O. Aa. Solheim, Volume and Volatility in the FX-Market: Does it matter who you are?, October 2002

787 John Evans and John Fingleton, Entry Regulation and the Influence of an Incumbent Special Interest Group, October 2002

788 Wolfgang Ochel, International Comparisons and Transfer of Labour Market Institutions, October 2002

789 B. Gabriela Mundaca, Moral Hazard Effects of Bailing out under Asymmetric Information, October 2002 
790 Gene M. Grossman and Edwin L.-C. Lai, International Protection of Intellectual Property, October 2002

791 John Hassler, José V. Rodriguez Mora, Kjetil Storesletten, and Fabrizio Zilibotti, A Positive Theory of Geographic Mobility and Social Insurance, October 2002

792 Paul De Grauwe and Marianna Grimaldi, The Exchange Rate in a Model with Heterogeneous Agents and Transactions Costs, October 2002

793 Guido Friebel and Mariassunta Giannetti, Fighting for Talent: Risk-shifting, Corporate Volatility, and Organizational Change, October 2002

794 Jan Erik Askildsen, Badi H. Baltagi, and Tor Helge Holmås, Will Increased Wages Reduce Shortage of Nurses? A Panel Data Analysis of Nurses' Labour Supply, October 2002

795 Marko Köthenbürger and Panu Poutvaara, Social Security Reform and Intergenerational Trade: Is there Scope for a Pareto-Improvement?, October 2002

796 Paul De Grauwe and Laura Rinaldi, A Model of the Card Payment System and the Interchange Fee, October 2002

797 Volker Böhm and Tomoo Kikuchi, Dynamics of Endogenous Business Cycles and Exchange Rate Volatility, October 2002

798 Mariam Camarero, Javier Ordóñez, and Cecilio Tamarit, The Euro-Dollar Exchange Rate: Is it Fundamental?, October 2002

799 Misa Tanaka, How Do Bank Capital and Capital Adequacy Regulation Affect the Monetary Transmission Mechanism?, October 2002

800 Jörg Baten and Andrea Wagner, Autarchy, Market Disintegration, and Health: The Mortality and Nutritional Crisis in Nazi Germany, 1933-1937, October 2002

801 Saku Aura, Uncommitted Couples: Some Efficiency and Policy Implications of Marital Bargaining, October 2002

802 Wolfram F. Richter, Delaying Integration of Immigrant Labor for the Purpose of Taxation, October 2002

803 Gil S. Epstein and Shmuel Nitzan, The Politics of Randomness, October 2002

804 John Hassler and José V. Rodriguez Mora, Should UI Benefits Really Fall over Time?, October 2002

805 Friedrich Breyer and Stefan Felder, The Dead-anyway Effect Revis(it)ed, October 2002

806 Assar Lindbeck and Solveig Wikström, E-exchange and the Boundary between Households and Organizations, November 2002 
807 Dieter Bös, Contests Among Bureaucrats, November 2002

808 Steven Brakman, Harry Garretsen, and Marc Schramm, The Strategic Bombing of German Cities during World War II and its Impact on City Growth, November 2002

809 Florian Englmaier and Achim Wambach, Contracts and Inequity Aversion, November 2002

810 Sarbajit Sengupta, Delegating Recruitment under Asymmetric Information, December 2002

811 Rajshri Jayaraman, On the Partial Public Provision of a Private Good, December 2002

812 Stéphanie Stolz, Banking Supervision in Integrated Financial Markets: Implications for the EU, December 2002

813 Christian Keuschnigg, Taxation of a Venture Capitalist with a Portfolio of Firms, December 2002

814 Inés Macho-Stadler and David Pérez-Castrillo, Settlement in Tax Evasion Prosecution, December 2002

815 Rainer Niemann and Dirk Simons, Costs, Benefits, and Tax-induced Distortions of Stock Option Plans, December 2002

816 Jan-Egbert Sturm and Barry Williams, Deregulation, Entry of Foreign Banks and Bank Efficiency in Australia, December 2002

817 V. Anton Muscatelli, Patrizio Tirelli, and Carmine Trecroci, Monetary and Fiscal Policy Interactions over the Cycle: Some Empirical Evidence, December 2002

818 Claude Hillinger, A General Theory of Price and Quantity Aggregation and Welfare Measurement, December 2002

819 Erkki Koskela and Ronnie Schöb, Optimal Capital Taxation in Economies with Unionised and Competitive Labour Markets, December 2002

820 Sheilagh Ogilvie, Guilds, Efficiency, and Social Capital: Evidence from German ProtoIndustry, December 2002

821 Hans Gersbach and Verena Liessem, Financing Democracy, December 2002

822 Costas Hadjiyiannis, Panos Hatzipanayotou, and Michael S. Michael, Optimal Tax Policies with Private-Public Clean-Up, Cross-Border Pollution and Capital Mobility, December 2002

823 François Ortalo-Magné and Sven Rady, Homeownership: Low Household Mobility, Volatile Housing Prices, High Income Dispersion, December 2002 